\title{
Olfactory Systems in Mate Recognition and SeXual Behavior
}

\author{
Matthieu Keller, ${ }^{\star, t, \neq}$ Delphine Pillon, ${ }^{,, t, \neq}$ and Julie Bakker ${ }^{\S, \uparrow, \#}$
}

\section{Contents}

I. Introduction

II. A Short Introduction to the Organization of the Accessory and Main Olfactory Subsystems

A. Architecture of the main olfactory system

B. Neuroanatomical organization of the accessory olfactory system

C. Main and accessory olfactory pathways impact partly overlapping neuroanatomical targets in limbic or hypothalamic structures

III. Both MOS and AOS Are Functionally Involved in Pheromonal Processing

IV. Involvement of Both Olfactory Systems in the Control of Mate Discrimination and Sexual Behavior

A. Pheromonal control of mate discrimination $\quad 341$

B. Pheromonal control of sexual behavior 342

$\begin{array}{ll}\text { V. General Conclusions } & 344\end{array}$

$\begin{array}{ll}\text { Acknowledgments } & 345\end{array}$

$\begin{array}{ll}\text { References } & 345\end{array}$

\section{Abstract}

Olfactory signals play an important role so that breeding efforts are synchronized with appropriate social and environmental circumstances. In this context, the mammalian olfactory system is characterized by the existence of several olfactory subsystems that have evolved to process olfactory information. While the vomeronasal (or accessory) olfactory system is usually conceived as being involved in the processing of pheromonal signals due to its close connections

\footnotetext{
* INRA, UMR 85 Physiologie de la Reproduction et des Comportements, Nouzilly, France

CNRS, UMR 6175, Nouzilly, France

* Université François Rabelais de Tours, Tours, France

$\S$ Neuroendocrinologie du Comportement, GIGA-Neurosciences, University of Liège, Belgium

- Netherlands Institute for Neuroscience, Amsterdam, The Netherlands

\# Medical Center, Vrije Universiteit, Amsterdam, The Netherlands
} 
with the reproductive hypothalamus, the main olfactory system is, by contrast, considered as a general analyzer of volatile chemosignals, especially those that are used for the social identification of conspecifics. In fact, several recent sets of experiments suggest that both the main and accessory olfactory systems have the ability to process partly overlapping pheromonal chemosignals and that both systems converge at a downstream level of pheromonal processing. As a consequence, both systems have the ability to support complimentary aspects in mate discrimination and sexual behavior. However, the relative roles played by these systems and their interactions are at present still far from being understood. () 2010 Elsevier Inc.

\section{INTRODUCTION}

In order to maximize reproductive success, animals have evolved neural and endocrine mechanisms to coordinate breeding efforts with appropriate social and environmental circumstances. Among the social factors that influence mammalian reproductive function, olfaction is probably the most widespread and powerful. Indeed, chemical cues called pheromones are used to communicate species-specific information that modulates the reproductive behavior or physiology of the receiver individual. Pheromones have been shown to act as major regulators of all stages of reproductive behavior, including mating (Keller et al., 2009), motheryoung interactions at birth (Lévy and Keller, 2009; Lévy et al., 2004), or sexual maturation (Vandenbergh, 1969). In the context of sexual behavior, pheromones are required to identify suitable mating partner or to trigger subsequent sexual motivation and copulatory behavior (Keller et al., 2008).

In this review, we will refer to pheromones as chemosignals produced and released by individuals and processed by individuals of the same species and leading to short-term behavioral changes or more long-term physiological changes in the receiver individual (Karlson and Luscher, 1959). Although this rather simple definition is usually well accepted and shared, leading us to use the concept in a wide variety of contexts, readers should be aware that the concept is however controversial and that much more restrictive definitions can be sometimes used (Beauchamp et al., 1976 or see reviews such as Brennan and Zufall, 2006 or Wyatt, 2003 for detailed analysis of current concepts and definitions related to pheromones). As a consequence, some of the examples depicted as being pheromonal effects may not always be shared by some investigators.

In addition, pheromones, as other olfactory chemosignals, are processed by the olfactory system. Interestingly, one of the specificity of the olfactory system, in comparison to other sensory systems, is the existence of various subsystems involved in the detection and processing of chemosignals 
(Munger et al., 2009; Tirindelli et al., 2009). These olfactory subsystems have evolved so that they differ in their molecular/genetic basis, in their peripheral and central anatomy as well as in their function. However, these systems may also have complimentary roles in sustaining pheromonedependent behaviors (for review please refer to Baum and Kelliher, 2009; Keller et al., 2009; Kelliher, 2007). Therefore, an old-standing question in the field is to know the relative involvement of each of these subsystems in the control of pheromone-dependent behaviors. Among the various olfactory subsystems that have been identified so far, the main and the accessory (or vomeronasal) olfactory systems are probably the best characterized and even if a growing number of studies have shown the existence of other olfactory subsystems, namely the Gruenberg ganglion or the septal organ of Masera, little is currently known about their involvement in the control of reproductive behaviors (Munger et al., 2009). As a consequence, this review will only concentrate on the relative roles of both main and accessory olfactory systems in mammalian mate discrimination and sexual behavior.

\section{A Short Introduction to the Organization OF THE ACCESSORY AND MAIN OLFACTORY SUBSYSTEMS}

\section{A. Architecture of the main olfactory system}

In the main olfactory system (MOS), chemosignals are detected by olfactory receptors inserted into the plasma membrane of ciliated olfactory sensory neurons which are located in the main olfactory epithelium (MOE), lying at the end of the nasal cavity. Olfactory receptors are G protein-coupled seven transmembrane proteins encoded by approximately 1000 genes in rodents, thus forming the largest gene family in mammals (Buck and Axel, 1991). Beside olfactory receptors, another family of olfactory receptors, the trace amine associated-receptors, has been more recently identified in the MOE (Liberles and Buck, 2006). Readers interested in the genetic and molecular organization of olfactory detection and processing could refer to recent exhaustive reviews (Munger et al., 2009; Tirindelli et al., 2009).

MOE sensory neurons project their axons through the cribriform plate to the glomeruli of the main olfactory bulb (MOB), in which they make synapse with dendrites of mitral/tufted cells. In these MOB glomeruli, MOE sensory projections are precisely organized so that sensory neurons expressing a given odorant receptor send their axons to a few converging glomeruli with a fixed topographical localization (Buck, 2000). The mitral and tufted cells abutting these MOB glomeruli then transmit olfactory signals to various forebrain and limbic targets including the piriform or 


\section{Pheromones}

Main olfactory system

Accessory olfactory system

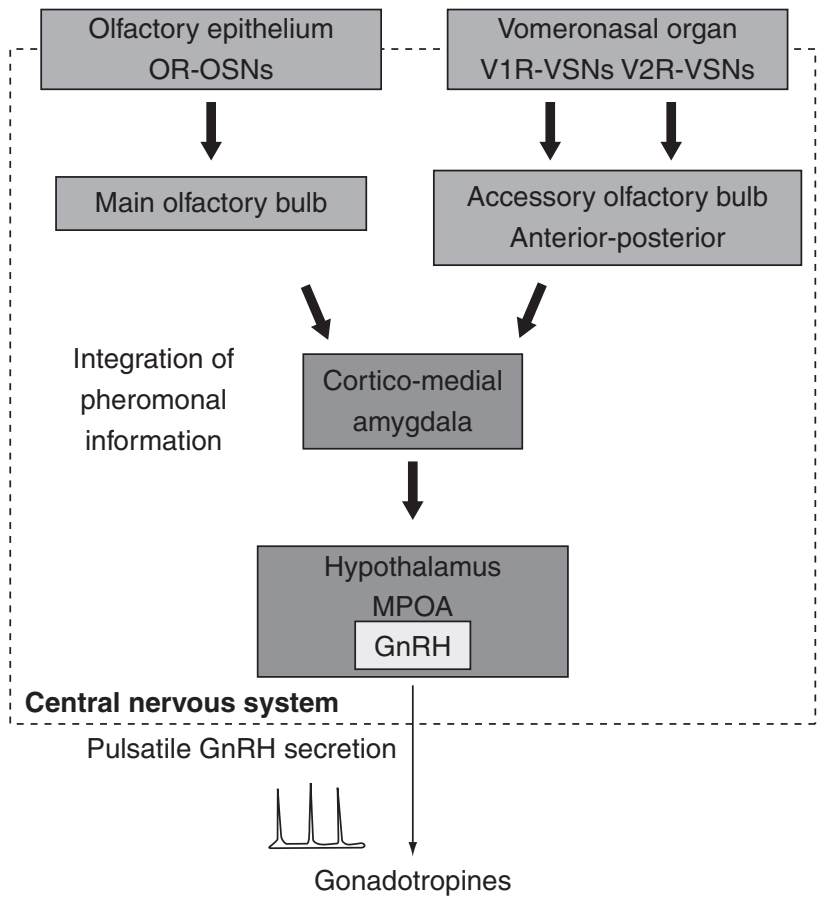

Physiological and/or behavioral modulation

of reproductive function

Figure 14.1 Schematic organization of mammalian main and accessory olfactory systems and their connections with the reproductive system at the level of GnRH neurons located in the reproductive hypothalamus.

the entorhinal cortices as well as the anterior cortical nucleus of the amygdala (Scalia and Winans, 1975, Fig. 14.1).

\section{B. Neuroanatomical organization of the accessory olfactory system}

The organization of the accessory olfactory system (AOS) differs widely, from a neuroanatomical perspective, in comparison to the one observed in the MOS. Indeed, the AOS is more closely related to the reproductive hypothalamus, thus being able to influence more long-term neuroendocrine or physiological changes. In this context, classical pheromonal effects 
mediated through the AOS include various examples impacting reproductive function such as modulation of puberty onset (Drickamer and Hoover, 1979; Vandenbergh, 1969), changes in estrus cyclicity (Whitten, 1956) or pregnancy block during the first stages of pregnancy (Brennan, 2009; Bruce, 1959).

In the AOS, the very first stage of pheromone detection takes place at the level of sensory neurons that are found in the vomeronasal organ (VNO; Fig. 14.1). The $\mathrm{VNO}$ is a sort of blind-ended tube that is running along the basis of the nasal septum and which opens via a narrow duct into the nasal cavity or into the mouth depending on species. Pheromones gain access to the lumen of the VNO by a vascular pumping mechanism activated once aroused animals investigate the olfactory source through direct physical contact (Meredith, 1994; Meredith and O'Connell, 1979). Once pheromones are pumped in the lumen of the VNO, pheromones then interact with vomeronasal receptors located on the membrane of VNO sensory neurons. These vomeronasal receptors have been classified in two distinct families: the vomeronasal type 1 (V1Rs) and type 2 (V2Rs) receptors (Munger et al., 2009; Tirindelli et al., 2009). The processing of pheromonal information through the vomeronasal system is obviously complex as it is segregated into two parallel streams. Indeed, both types of V1Rs- and V2Rs-sensory neurons are expressed in excluding regions of the VNO: while V1Rs-sensory neurons are expressed in the apical part of the VNO, near the lumen, V2Rs-sensory neurons are expressed in the more basal region (Brennan, 2004).

Such segregated organization between both streams of pheromonal information is conserved one step downstream at the level of the accessory olfactory bulb (AOB), where vomeronasal sensory neurons project their axons. Indeed, V1Rs-sensory neurons send projections exclusively to the rostral AOB, while V2Rs-sensory neurons project to its caudal part. This topographical segregation is thought to sustain functional differences as both AOB regions respond differentially to pheromonal stimuli in mice (Brennan et al., 1999; Halem et al., 2001). Finally, it has been shown that AOB mitral cells are only activated when mice contact various regions of the body of an anesthetized stimulus female, thus providing further support to the notion that the vomeronasal system is activated when animals investigate directly pheromonal source (Luo et al., 2003).

When leaving the AOB, mitral cells project to the medial nucleus of the amygdala, where the pheromonal informations processed segregated so far (rostral versus caudal parts of the vomeronasal pathway) express some degree of convergence into partly overlapping projections (Von Campenhausen and Mori, 2000). Olfactory information reaches then various hypothalamic and limbic regions highly involved in the regulation of reproductive function and behavior. These regions include especially the bed nucleus of the stria terminalis (BnST), the medial preoptic area (MPOA), and the ventromedial hypothalamus (VMN; Scalia and Winans, 1975). 


\section{Main and accessory olfactory pathways impact partly overlapping neuroanatomical targets in limbic or hypothalamic structures}

As exposed shortly above, both olfactory systems exhibit segregated detection and projection pathways at both peripheral (olfactory sensory neurons) and more central (olfactory bulbs) levels. However, a certain degree of convergence is observed between the two systems at the level of the cortical-medial amygdala (Gomez and Newman, 1992; Kevetter and Winans, 1981a,b; Meredith, 1991, 1998). Indeed, electrophysiological responses have been recorded in response to electrical stimulations of both the MOB and VNO at the single cell level (Licht and Meredith, 1987), thus suggesting that pheromonal signals mediated through both systems could interact and then impact the downstream network involved in the regulation of sexual behavior and including the BnST, MPOA, or VMN. In a reproductive context, another important site of cellular convergence of both olfactory systems is the gonadotropin-releasing hormone (GnRH) neurons that are found scattered in the MPOA. Indeed, it is widely accepted that the effects of pheromones on reproductive function are mainly mediated by GnRH neurons which represent the final output pathway of the neuronal network controlling fertility in all mammalian species. Several sets of experiments have now clearly demonstrated that both the vomeronasal and main olfactory subsystems project (at least indirectly) to $\mathrm{GnRH}$ neurons (Boehm et al., 2005), and various experiments suggest that pheromonal signals processed through these systems have the potential to activate these neurons (Coquelin et al., 1984; Meredith and Fewell, 2001; Pfeiffer and Johnston, 1994; Westberry and Meredith, 2003a,b).

\section{Both MOS and AOS ARe FunCtionally Involved in Pheromonal Processing}

The vomeronasal system is usually considered as the main focus for pheromonal research due to its close connection with the reproductive hypothalamus and is therefore conceived to mediate the physiological and neuroendocrine changes induced by pheromones. For example, lesioning any level of the vomeronasal pathway has been consistently shown to disrupt pheromonal effects such as puberty acceleration or pregnancy block (Bellringer et al., 1980; Lloyd-Thomas and Keverne, 1982; Lomas and Keverne, 1982). Using both in vitro electrophysiological and imaging methods, several groups have demonstrated that VNO sensory neurons can express very low threshold responses to various volatile pheromones (Del Punta et al., 2002; Leinders-Zufall et al., 2000). It is debatable whether these 
volatiles can have freely access to the $\mathrm{VNO}$ in the airstream and it is generally thought that they have to be transported into the VNO lumen, when the animals contact the pheromonal source, by carrier proteins belonging to the lipocalin family (Wysocki et al., 1980). Some members of this family, including the major urinary proteins (MUPs; Hurst et al., 2001) are now well characterized. Interestingly, these carrier proteins are also thought to serve by themselves for individual recognition, due to their high degree of polymorphism and their ability to stimulate the expression of the immediate early gene egr- 1 in specific regions of the AOB (Brennan et al., 1999; Hurst et al., 2001). Other example of rather nonvolatile pheromonal signal processed by the vomeronasal system includes the male-specific exocrine gland-secreting peptide 1 which is secreted from the extraorbital lacrimal gland. This peptide is transferred through direct contact to the female VNO, where it stimulates V2R-expressing vomeronasal sensory neurons and elicits sex-specific electrophysiological response (Kimoto et al., 2005). As a whole, these data suggest that the VNO has the ability to process a wide set of both volatile and peptide- or protein-related pheromonal chemosignals.

The case of the pregnancy block effect (also known as the Bruce effect) is a good example illustrating how pheromones detected by the AOS are able to induce long-term changes in the reproductive axis (Fig. 14.2). Indeed, the pregnancy block effects result from a neuroendocrine reflex triggered by the exposure of recently mated female mice to chemosignals from an unfamiliar male. The effect of male chemosignals on pregnancy is mediated by the suppression of prolactin release from the pituitary, due to increased dopamine release from neurons in the hypothalamic arcuate nucleus (Brennan, 2009). Prolactin is luteotrophic in mice, and thus reduction in prolactin blood levels results in failure of the corpora lutea. The consequent reduction in circulating progesterone levels prevents embryo implantation and thus terminates pregnancy and induces a return into estrus.

Beside the role of the AOS in pheromonal communication, it has also been known for a long time that the MOS has the ability to detect and process various pheromones. Indeed, the MOS is involved in the processing of volatile pheromonal signals related to social attraction and recognition, thus allowing animals to discriminate conspecifics according to their reproductive status. Indeed, urine consists of a mixture of distinct chemicals that vary, among others, according to the sex or physiology of the emitter (Andreolini et al., 1987; Jemiolo et al., 1989). For example, the volatile urinary compound (methylthio)-methanethiol (MTMT), that is present in male mice urine, activates a subset of mitral cells in the female MOB, and enhances female attractiveness of gonadectomized male urine when added to it (Lin et al., 2005, Fig. 14.3). The MOS is also involved in the processing of the volatile steroid androstenone which is found in boar saliva and triggers tonic immobilization when detected by receptive sows (Dorries et al., 1995, 1997). 


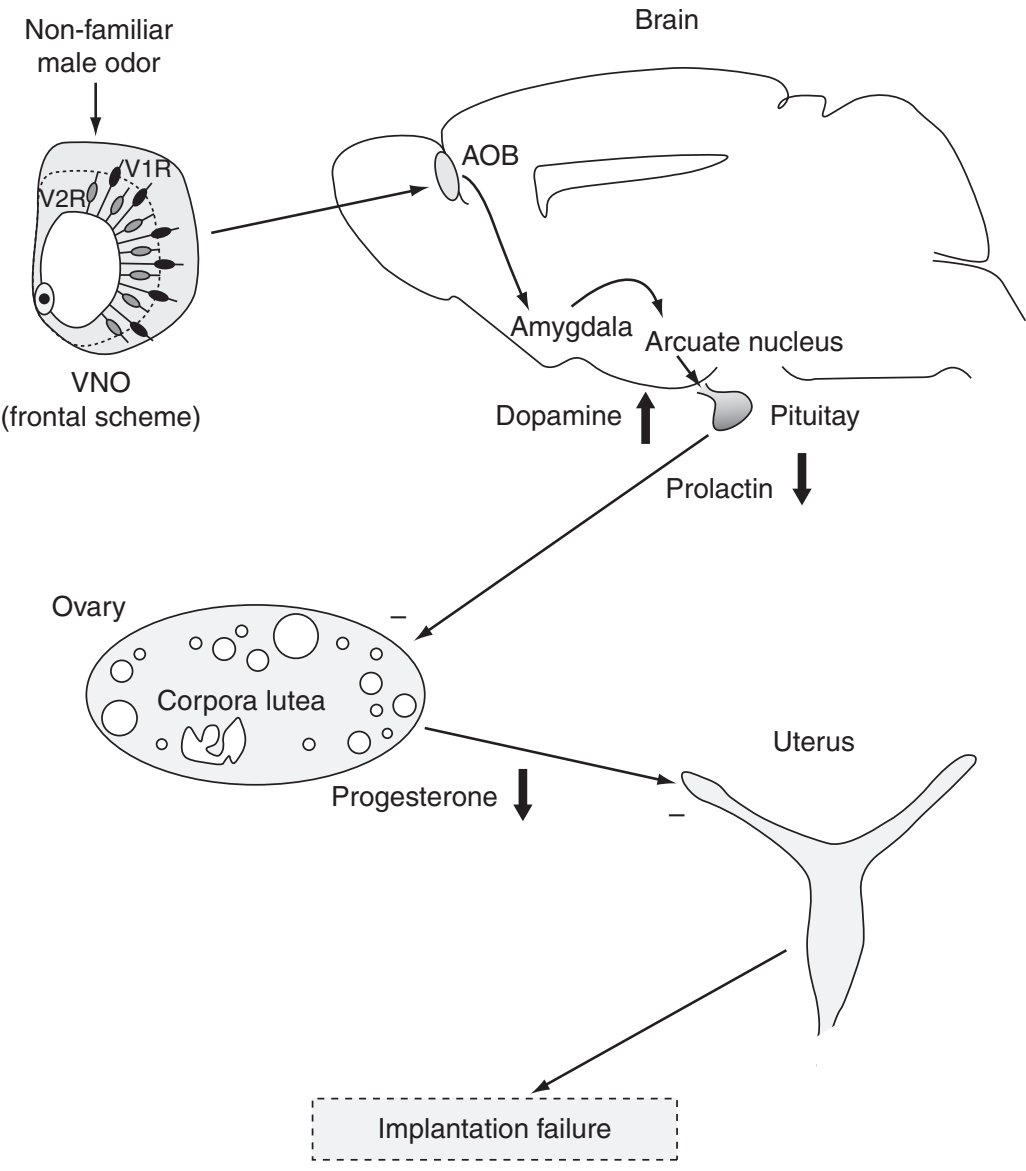

Figure 14.2 Schematic in the pregnancy block effect in mice. Exposure to the odor of an unfamiliar male triggers a neuroendocrine reflex leading to implantation failure. Unfamiliar male odor is processed by the vomeronasal organ, the accessory olfactory bulb, and finally the arcuate nucleus where it induces a decrease in prolactin secretion from the pituitary. The reduction in circulating prolactin results in failure of the corpora lutea and the consequent reduction in circulating progesterone levels prevents embryo implantation and thus terminates pregnancy and induces a return into estrus

This volatile chemosignal still produces its effect in sows having their VNO blocked, thus demonstrating that androstenone is detected and processed by the MOS. The MOS is also involved in the processing of male pheromones in the context of the male effect in sheep. This pheromonal effect is characterized by a reactivation of the whole gonadotropic axis in ewes exposed to ram pheromones during the seasonal period of anestrous (Cohen-Tannoudji et al., 1989; Delgadillo et al., 2009; Gelez and Fabre-Nys, 2004). In this example again, lesioning the AOS does not affect the LH and ovulatory 
A<smiles>C/C=C(\C)C=O</smiles>

2-Methylbut-2-enal

C<smiles>C=C/C(C)=C/C/C=C(\C)CCC=C(C)C</smiles>

E, E $\alpha$-farnesene<smiles>CSCS</smiles>

Methylthio methanethiol
B<smiles>C[C@]12CC=CC1C1CC[C@H]3CC(=O)CC[C@]3(C)C1CC2</smiles>

Androstenone<smiles>CC(C)C1=NCCS1</smiles>

2-sec-butyl-4, 5-dihydrothiazole<smiles>CCC(=O)CCC(C)(C)O</smiles>

6-Hydroxy-6-methyl-3-heptanone

Figure 14.3 A few examples of mammalian pheromones involved in the control of mate recognition and sexual behavior. (A) 2-Methylbut-2-enal, the rabbit mammary pheromone that is released in the milk of the female rabbit and triggers the stereotyped nipple-search behavior. (B) Androstenone is released from the boar saliva and induces tonic immobility in receptive sow. (C) Some pheromones found in male mice urine and mediating various physiological or behavioral responses in the female, including mate discrimination or puberty acceleration.

responses of the ewe to the ram. Finally, quite convincing pheromonal effects have been demonstrated in humans who do not have a functional vomeronasal system (Meredith, 2001; Wysocki and Preti, 2004). Indeed, it has been demonstrated that exposing women to axillaries extracts from women in the follicular phase of their menstrual cycle shortens the length of the recipient's menstrual cycle (Stern and McClintock, 1998). Male and female axillaries stimulations have also been demonstrated to induce changes in $\mathrm{LH}$ pulses and mood in recipient women (Preti et al., 2003; Shinohara et al., 2001). Additionally, these kind of putative pheromonal signals only induce brain activation, revealed by functional brain imaging, in human with intact main olfactory function (Savic et al., 2009). Finally, women can also differentiate and even show preference for the odor of male individuals with a dissimilar MHC genetic background (i.e., a different major histocompatibility complex; Jacob et al., 2002), thus giving some support to the existence of an MOSmediated pheromonal communication in human in a reproductive context.

As a whole, the view emerging from previous examples is that each olfactory system has the ability to process specific chemosignals. However, this functional dichotomy is only schematic because sensory neurons of 
both systems have the ability to detect partly overlapping sets of chemosignals and to process them in parallel. Indeed, calcium imaging studies performed on in vitro preparation of nasal tissue have shown that some sensory neurons respond to MHC-related peptides in both the VNO and the MOE (Spehr et al., 2006a). The mechanisms underlying the detection of MHC peptides by VNO or MOE sensory neurons seem however to differ between both olfactory systems. Indeed, not only do thresholds of sensory neuron responses to MHC peptides differ in both VNO and MOE (Leinders-Zufall et al., 2004; Spehr et al., 2006b), but their detection also depends on distinct sets of transduction mechanisms. For example, the drug 2-aminoethoxydiphenylborate is able to inhibit local field potential to MHC peptides in the VNO but not in the MOE. Another example can be illustrated with the case of the volatile 2-heptanone; its detection appears to be dependent on the Trp2 (transient receptor potential cation 2 channel) gene in the VNO, while in the MOE, detection of 2-heptanone depends on the CNGA2 (Leypold et al., 2002; Lin et al., 2004), a channel that is only expressed in the MOE. At the behavioral level, the processing of these same olfactory signals is apparently not redundant as specific activation of each system leads obviously to different behavioral outputs. Thus, in the AOS, MHC-class I peptides signals have been shown to be used in the context of the Bruce effect (Leinders-Zufall et al., 2004) while processing of MHCclass I peptides in the MOE supports social preferences (Spehr et al., 2006b), thus demonstrating that MHC processing via the MOE does not replace vomeronasal inputs.

\section{InVOlvement OF Both Olfactory Systems in THE CONTROL OF MATE Discrimination AND Sexual Behavior}

Sexual behavior, as many socially motivated behaviors, can be divided into two phases: a motivational phase where pheromones allow partners to attract and identify each other (mate attraction and discrimination), which is followed by a sequence of interactions leading to copulation (consummatory sexual behavior). Attraction to as well as discrimination of the opposite-sex partner is usually thought to be dependent upon the main olfactory pathway as it is conceived as a general analyzer of the numerous volatile odors present in the environment, while the AOS is thought to control copulatory behavior due to its connections with the reproductive hypothalamus (Keverne, 2004). As we will see, this dichotomy is also rather schematic and both MOS and AOS can participate to the discrimination of a potential mate as well as the control of sexual behavior, depending on situations and/or species. 


\section{A. Pheromonal control of mate discrimination}

The usual conception that attraction/discrimination toward the opposite sex involves the MOS is based on the observation that olfactory sexual discrimination can be achieved from a distance, on the basis of volatile olfactory cues only (as mentioned in part II, it is usually admitted that pheromones can gain access to the VNO only after direct physical investigation of the olfactory source). Such results have been repeatedly observed in different behavioral paradigms including habituation/dishabituation tests (Baum and Keverne, 2002; Pierman et al., 2006), Y-maze preference tests (Keller et al., 2006a,b; Pankevich et al., 2006), or olfactometer studies based on go/no-go conditioning procedures (Keller et al., 2009; Wesson et al., 2006). In support to these results, it has been shown at the neurobiological level that stimulation with urinary volatiles or even with specific volatile urinary compounds such as MTMT, can induce clear MOB electrophysiological responses (Lin et al., 2005). In addition, other experiments using mapping of immediate early genes expression showed that stimulation with urinary volatiles induced specific activation patterns at the level of the MOB glomerular cell layer (Martel and Baum, 2007; Martel et al., 2007). Finally, the involvement of the MOS in mate discrimination has been confirmed by lesion of MOE function using intranasal application of zinc sulfate or intraperitonal injections of dichlobenil, both being chemicals destroying MOE sensory neurons without damaging the vomeronasal sensory neurons (Keller et al., 2006a,b; Yoon et al., 2005). MOS lesion abolished the usual preference for opposite-sex olfactory cues usually observed in both sexes when tested in a Y-maze. Interestingly, the effect of zinc sulfate lesioning was not only obtained when the animals were provided with volatile stimuli only, but also when direct contact with the olfactory source was provided, thus allowing the AOS potential access to both volatile and nonvolatile olfactory cues. This latter result suggests that volatiles detected and processed through the MOS are needed for the subsequent attraction of the animal toward deposit sources. This is in line with experiments performed in OMP-ntr mice, where the enzymatic activity of a nitroreductase enzyme is able to induce specific destruction of MOE sensory neurons and as a result disrupts the ability of female mice to localize male urinary deposit in the home cage (Ma et al., 2002).

Complementary to the results described above, surgical ablation of the $\mathrm{VNO}$ is clearly ineffective in disrupting mate discrimination in both male and female mice (Keller et al., 2006c; Pankevich et al., 2004, 2006). Indeed, VNO-lesioned animals can perfectly discriminate body or urinary volatiles in a habituation/dishabituation test as well as express opposite-sex preference using volatile odors. Such a lack of VNO involvement in mate discrimination has also been shown in female ferrets where VNO lesion is ineffective in disrupting opposite-sex discrimination (Woodley et al., 2004). 
By contrast, blocking the nares of the animals produced deficits in both male and female ferrets (Kelliher and Baum, 2001). Other evidence comes from pig where VNO duct occlusion failed to disrupt female attraction toward the boar pheromone, androstenone (Dorries et al., 1997). These results demonstrating the lack of a role for the $\mathrm{VNO}$ in mate discrimination have been confirmed by lesions performed downstream in the AOS, at the level of the AOB (Jakupovic et al., 2008; Martinez-Ricos et al., 2008).

Despite these convergent results, a role for the VNO in sex discrimination and mate recognition has been claimed by studies using Trp2-KO male mice (Leypold et al., 2002; Stowers et al., 2002). Deletion of Trp2 results in a large reduction of electrophysiological responses in VNO sensory neurons after exposure to urinary odorants and at the behavioral level, Trp2-KO male mice show indiscriminate attempts of mounts toward male and female stimulus subjects (Leypold et al., 2002; Stowers et al., 2002). Based on these data, the authors concluded that the VNO is needed for mate recognition. However, neither study measured olfactory sex discrimination directly, and therefore it remains questionable whether Trp2-KO males can discriminate between the sexes on the basis of pheromonal chemosignals. Fortunately, these results can be reconciled with previous findings because it has been shown that Trp2-KO mice still exhibit electrophysiological responses after MHC-class I peptides stimulation (Kelliher et al., 2006). Furthermore, these mice show a pregnancy block effect when they are exposed to the odor of a strange male. These results suggest that Trp2 ablation is not equivalent to a total elimination of VNO function. Instead, it seems likely that some vomeronasal function is retained in $\operatorname{Trp} 2-\mathrm{KO}$ mice. It is also possible that developmental compensatory processes allow some recovery of vomeronasal function in these animals.

Finally, in contrast to the data presented so far, the rat appears as an exception because lesion of the AOS impacts attraction to opposite-sex odors quite extensively (Ichikawa, 1989; Romero et al., 1990), therefore leading to extreme caution when extrapolating results from one species to another.

\section{B. Pheromonal control of sexual behavior}

\section{Pheromonal control of male sexual behavior}

The involvement of the MOS versus the AOS in the expression of sexual behavior is a subject of controversy. In the male, the involvement of VNO in copulatory behavior seems to vary greatly according to species. While in hamsters or prosimian primates (Microcebus murinus), surgical destruction of the VNO had quite important effects on male sexual behavior (Aujard, 1997; Powers and Winans, 1975), this seems not to be the case in male mice. Indeed, lesioning the VNO does not (Pankevich et al., 2004) or only partly impact sexual behavior (Clancy et al., 1984). As well, Trp2-KO male also 
demonstrate normal copulatory abilities (Stowers et al., 2002), thus suggesting a role for the MOS (Keller et al., 2006a). In support to this hypothesis, male mice sexual behavior has been shown to be more generally dependent on the MOS. Indeed, various studies, using either chemical lesions of the MOE with dichlobenil (Yoon et al., 2005) or zinc sulfate (Keller et al., 2006b) or using genetically engineered mice lacking CNGA2 (Mandiyan et al., 2005) demonstrated a clear disruption of sexual behavior after destruction/inactivation of the MOE.

Interestingly, sexual experience is a factor allowing the integration of chemosignals originating from both MOS and AOS. Indeed, in hamsters, the control of male sexual behavior is varying according to previous sexual experience (Meredith, 1986; Pfeiffer and Johnston, 1994). In sexually naïve males, severe deficits in sexual behavior are observed in VNO-lesioned animals, thus showing that these inputs are needed for normal copulatory performance in these animals. By contrast, once animals have gained sexual experience, either main or vomeronasal inputs are sufficient for mating to occur. Only lesioning of both systems can impair copulation in these sexually experienced males. It has been suggested that the effect of olfactory deprivation on sexual behavior may be mediated by GnRH neurons. Indeed, GnRH cells receive olfactory information from both the MOS and the AOS. At the same time, an intracerebroventricular injection of $\mathrm{GnRH}$ is able to overcome the absence of VNO olfactory inputs in a way similar to that of sexual experience (Fernandez-Fewell and Meredith, 1994, 1995; Meredith, 1998; Meredith and Howard, 1992). Therefore, one hypothesis is that sexual experience modulates the relative functional efficiency of these MOB-to-GnRH neuron connections: these connections gaining functional efficiency only after a sufficient amount of sexual experience. In this context, female chemosensory cues are able to induce a higher Fos immunocytochemical labeling in the MPOA in sexually experienced than in inexperienced males. Compensation between both olfactory systems according sexual experience seems however not to be a general rule. For example, in male mice MOE lesion disrupts sexual behavior in both naïve and sexually experienced animals (Keller et al., 2006b), suggesting that vomeronasal inputs are not able to sustain copulation by themselves in mice and underlying differences between species.

\section{Pheromonal control of female sexual behavior}

In the female, early studies (Edwards and Burge, 1973; Thompson and Edwards, 1972) suggested a role for the MOS in the display of female sexual receptivity, since destruction of the MOE by intranasal infusion with zinc sulfate attenuated lordosis behavior. In accordance with these results, recent experiments also confirmed that MOE zinc sulfate lesion reduced lordosis (Keller et al., 2006a). An explanation for these effects is that deprivation of MOS sensory input may induce less activation of the centers regulating 
lordosis in the brain, for example the VMN, and as a consequence disrupts lordosis behavior. However, these effects of MOE lesions are clearly not as effective in disrupting lordosis as VNO lesions. Indeed, VNO lesions greatly abolished lordosis behavior in females of various species including rats (Rajendren et al., 1990), mice (Keller et al., 2006c), hamsters (MackaySim and Rose, 1986), or voles (Curtis et al., 2001). Intriguingly, studies on the role of the VNO in pregnancy block effect in mice showed that VNO ablation did not prevent female mice from becoming pregnant (Kelliher et al., 2006; Lloyd-Thomas and Keverne,1982), suggesting that the VNO may not mediate female sexual receptivity in mice. However, both sets of data can be reconciled because it has been shown that the disruptive consequences of VNO lesions can be partly overcome over time and long-term exposure to the male. For example, the lordosis quotient of VNO-lesioned female rats increased after prolonged exposure to the male (Rajendren et al., 1990), suggesting that some compensatory mechanisms can occur over time. The degree of sexual or olfactory sensory experience prior to VNO removal may also play a role in these compensatory mechanisms (Martínez-García et al., 2009).

\section{General Conclusions}

In conclusion, we have reviewed the current conceptions of how the mammalian main and accessory olfactory subsystems interact to detect and process partially overlapping sets of pheromonal signals, giving rise to a model that involves parallel processing of the same molecules but through different mechanisms leading to specific behavioral outputs. Indeed, the most salient feature of this review is that there are no general rules that allow classification of the AOS more as a pheromone detector than the MOS. Consequently, both systems should be conceived as complementary rather than as separate pathways for mate discrimination and the stimulation of sexual motivation and behavior. Further experimentation will be needed to understand how chemosensory cues are integrated with hormonal and neuroendocrine factors to control courtship and mating behaviors, especially at the level of the hypothalamus. In addition, the reader must remind that most of the data reported in this manuscript refer to rodent literature. This is justified by the fact that the most recent advances in the field have been performed in these species and also according to the great importance of olfactory communication in these species, but this should lead to some caution when extrapolating to other species, as by definition pheromones are species-specific signals. Therefore, great heuristic value will be undoubtedly provided by comparative research in relation to speciesspecific evolutionary and ecological constraints. 


\section{ACKNOWLEDGMENTS}

Matthieu Keller is a CNRS research associate (France). Delphine Pillon is associate professor at the University of Tours. Julie Bakker is an FNRS research associate. This work has been performed under the support of ANR 2009 CESA-006-02.

\section{REFERENCES}

Andreolini, F., Jemiolo, B., and Novotny, M. (1987). Dynamics of excretion of urinary chemosignals in the house mouse (Mus musculus) during the natural estrous cycle. Experientia 43, 998-1002.

Aujard, F. (1997). Effect of vomeronasal organ removal on male socio-sexual responses to female in a prosimian primate (Microcebus murinus). Physiol. Behav. 6, 1003-1008.

Baum, M. J., and Kelliher, K. R. (2009). Complementary roles of the main and accessory olfactory systems in mammalian mate recognition. Annu. Rev. Physiol. 71, 141-160.

Baum, M. J., and Keverne, E. B. (2002). Sex difference in attraction thresholds for volatile odors from male and estrous female mouse urine. Horm. Behav. 41, 213-219.

Beauchamp, G. K., Doty, R. L., Moulton, D. G., and Mugford, R. A. (1976). The pheromone conception mammalian chemical communication: A critique. In "Mammalian Olfaction, Reproductive Success and Behavior," (R. L. Doty, Ed.), pp. 144-160. NewYork, Academic Press.

Bellringer, J. F., Pratt, H. P., and Keverne, E. B. (1980). Involvement of the vomeronasal organ and prolactin in pheromonal induction of delayed implantation in mice. J. Reprod. Fertil. 59, 223-228.

Boehm, U., Zou, Z., and Buck, L. B. (2005). Feedback loops link odor and pheromone signaling with reproduction. Cell 123, 683-695.

Brennan, P. A. (2004). The nose knows who's who: Chemosensory individuality and mate recognition in mice. Horm. Behav. 46, 231-240.

Brennan, P. A. (2009). Outstanding issues surrounding vomeronasal mechanisms of pregnancy block and individual recognition in mice. Behav. Brain Res. 200, 287-294.

Brennan, P. A., and Zufall, F. (2006). Pheromonal communication in vertebrates. Nature 444, 308-315.

Brennan, P. A., Schellinck, H. M., and Keverne, E. B. (1999). Patterns of expression of the immediate-early gene egr-1 in the accessory olfactory bulb of female mice exposed to pheromonal constituents of male urine. Neuroscience 90, 1463-1470.

Bruce, H. M. (1959). An exteroceptive block to pregnancy in the mouse. Nature 184, 105.

Buck, L. B. (2000). The molecular architecture of odor and pheromone sensing in mammals. Cell 100, 611-618.

Buck, L. B., and Axel, R. (1991). A novel multigene family may encode odorant receptors: A molecular basis for odor recognition. Cell 65, 175-187.

Clancy, A. N., Coquelin, A., Macrides, F., Gorski, R. A., and Noble, E. P. (1984). Sexual behavior and aggression in male mice: Involvement of the vomeronasal system. J. Neurosci. 4, 2222-2229.

Cohen-Tannoudji, J., Lavenet, C., Locatelli, A., Tillet, Y., and Signoret, J. P. (1989). Non involvement of the accessory olfactory system in the LH response of anoestrous ewes to male odour. J. Reprod. Fertil. 86, 135-144.

Coquelin, A., Clancy, A. N., Macrides, F., Noble, E. P., and Gorski, R. A. (1984). Pheromonally induced release of luteinizing hormone in male mice: Involvement of the vomeronasal system. J. Neurosci. 4, 2230-2236. 
Curtis, J. T., Liu, Y., and Wang, Z. (2001). Lesions of the vomeronasal organ disrupt mating induced pair bonding in female prairie voles (Microtus ochrogaster). Brain Res. 901, 167-174.

Del Punta, K., Puche, A., Adams, N. C., Rodriguez, I., and Mombaerts, P. (2002). A divergent pattern of sensory axonal projections is rendered convergent by second-order neurons in the accessory olfactory bulb. Neuron 35, 1057-1066.

Delgadillo, J. A., Gelez, H., Ungerfeld, R., Hawken, P. A., and Martin, G. B. (2009). The 'male effect' in sheep and goats-Revisiting the dogmas. Behav. Brain Res. 200, 304-314.

Dorries, K. M., Adkins-Regan, E., and Halpern, B. P. (1995). Olfactory sensitivity to the pheromone, androstenone, is sexually dimorphic in the pig. Physiol. Behav. 57, 255-259.

Dorries, K. M., Adkins-Regan, E., and Halpern, B. P. (1997). Sensitivity and behavioral responses to the pheromone androstenone are not mediated by the vomeronasal organ in domestic pigs. Brain Behav. Evol. 49, 53-62.

Drickamer, L. C., and Hoover, J. E. (1979). Effects of urine from pregnant and lactating female house mice on sexual maturation of juvenile females. Dev. Psychobiol. 12, 545-551.

Edwards, D. A., and Burge, K. G. (1973). Olfactory control of the sexual behavior of male and female mice. Physiol. Behav. 11, 867-872.

Fernandez-Fewell, G. D., and Meredith, M. (1994). c-Fos expression in vomeronasal pathways of mated or pheromone-stimulated male golden hamsters: Contributions from vomeronasal sensory input and expression related to mating performance. J. Neurosci. 14, 3643-3654.

Fernandez-Fewell, G. D., and Meredith, M. (1995). Facilitation of mating behavior in male hamsters by LHRH and Ac LHRH 5-10: Interaction with the vomeronasal system. Physiol. Behav. 57, 213-221.

Gelez, H., and Fabre-Nys, C. (2004). The "male effect" in sheep and goats: A review of the respective roles of the two olfactory systems. Horm. Behav. 46, 257-271.

Gomez, D. M., and Newman, S. W. (1992). Differential projections of the anterior and posterior regions of the medial amygdaloid nucleus in the Syrian hamster. J. Comp. Neurol. 317, 195-218.

Halem, H. A., Baum, M. J., and Cherry, J. A. (2001). Sex difference and steroid modulation of pheromone-induced immediate early genes in the two zones of the mouse accessory olfactory system. J. Neurosci. 21, 2474-2480.

Hurst, J. L., Payne, C. E., Nevison, C. M., Marie, A. D., Humphries, R. E., Robertson, D. H., Cavaggioni, A., and Beynon, R. J. (2001). Individual recognition in mice mediated by major urinary proteins. Nature 414, 631-634.

Ichikawa, M. (1989). Recovery of olfactory behavior following removal of accessory olfactory bulb in adult rat. Brain Res. 498, 45-52.

Jacob, S., McClintock, M. K., Zelano, B., and Ober, C. (2002). Paternally inherited HLA alleles are associated with women's choice of male odor. Nat. Genet. 30, 175-179.

Jakupovic, J., Kang, N., and Baum, M. J. (2008). Effect of bilateral accessory olfactory bulb lesions on volatile urinary odor discrimination and investigation as well as mating behavior in male mice. Physiol. Behav. 93, 467-473.

Jemiolo, B., Andreolini, F., Xie, T. M., Wiesler, D., and Novotny, M. (1989). Pubertyaffecting synthetic analogs of urinary chemosignals in the house mouse, Mus domesticus. Physiol. Behav. 46, 293-298.

Karlson, P., and Luscher, M. (1959). 'Pheromones': A new term for a class of biologically active substances. Nature 183, 55-56.

Keller, M., Douhard, Q., Baum, M. J., and Bakker, J. (2006a). Destruction of the main olfactory epithelium reduces female sexual behavior and olfactory investigation in female mice. Chem. Senses 31, 315-323. 
Keller, M., Douhard, Q., Baum, M. J., and Bakker, J. (2006b). Sexual experience does not compensate for the disruptive effects of zinc sulfate-Lesioning of the main olfactory epithelium on sexual behavior in male mice. Chem. Senses 31, 753-762.

Keller, M., Pierman, S., Douhard, Q., Baum, M. J., and Bakker, J. (2006c). The vomeronasal organ is required for the expression of lordosis behaviour, but not sex discrimination in female mice. Eur. J. Neurosci. 23, 521-530.

Keller, M., Baum, M. J., and Bakker, J. (2008). Olfactory control of sex-recognition and sexual behavior in mice. In "Chemical Signals in Vertebrates XI," (J. L. Hurst, R. J. Beynon, S. C. Roberts, and T. D. Wyatt, Eds.), pp. 241-250. Springer-Verlag, New York.

Keller, M., Baum, M. J., Brock, O., Brennan, P., and Bakker, J. (2009). The main and the accessory olfactory systems interact in the control of mate recognition and sexual behavior. Behav. Brain Res. 200, 268-276.

Kelliher, K. R. (2007). The combined role of the main olfactory and vomeronasal systems in social communication in mammals. Horm. Behav. 52, 561-570.

Kelliher, K. R., and Baum, M. J. (2001). Nares occlusion eliminates heterosexual partner selection without disrupting coitus in ferrets of both sexes. J. Neurosci. 21, 5832-5840.

Kelliher, K. R., Spehr, M., Li, X. H., Zufall, F., and Leinders-Zufall, T. (2006). Pheromonal recognition memory induced by TRPC2-independent vomeronasal sensing. Eur. J. Neurosci. 23, 3385-3390.

Keverne, E. B. (2004). Importance of olfactory and vomeronasal systems for male sexual function. Physiol. Behav. 83, 177-187.

Kevetter, G. A., and Winans, S. S. (1981a). Connections of the corticomedial amygdala in the golden hamster. II. Efferents of the "olfactory amygdala". J. Comp. Neurol. 197, 99-111.

Kevetter, G. A., and Winans, S. S. (1981b). Connections of the corticomedial amygdala in the golden hamster. I. Efferents of the "vomeronasal amygdala". J. Comp. Neurol. 197, 81-98.

Kimoto, H., Haga, S., Sato, K., and Touhara, K. (2005). Sex-specific peptides from exocrine glands stimulate mouse vomeronasal sensory neurons. Nature 437, 898-901.

Leinders-Zufall, T., Lane, A. P., Puche, A. C., Ma, W., Novotny, M. V., Shipley, M. T., and Zufall, F. (2000). Ultrasensitive pheromone detection by mammalian vomeronasal neurons. Nature 405, 792-796.

Leinders-Zufall, T., Brennan, P., Widmayer, P., Chandramani, S. P., Maul-Pavicic, A., Jäger, M., Li, X. H., Breer, H., Zufall, F., and Boehm, T. (2004). MHC class I peptides as chemosensory signals in the vomeronasal organ. Science 306, 1033-1037.

Lévy, F., and Keller, M. (2009). Olfactory mediation of maternal behaviour in selected mammalian species. Behav. Brain Res. 200, 336-345.

Lévy, F., Keller, M., and Poindron, P. (2004). Olfactory regulation of maternal behavior in mammals. Horm. Behav. 46, 284-302.

Leypold, B. G., Yu, C. R., Leinders-Zufall, T., Kim, M. M., Zufall, F., and Axel, R. (2002). Altered sexual and social behaviors in trp2 mutant mice. Proc. Natl. Acad. Sci. USA 99, 6376-6381.

Liberles, S. D., and Buck, L. B. (2006). A class of chemosensory receptors in the olfactory epithelium. Nature 42, 645-650.

Licht, G., and Meredith, M. (1987). Convergence of main and accessory olfactory pathways onto single neurons in the hamster amygdala. Exp. Brain Res. 69, 7-18.

Lin, W., Arellano, J., Slotnick, B., and Restrepo, D. (2004). Odors detected by mice deficient in cyclic nucleotide-gated channel subunit A2 stimulate the main olfactory system. J. Neurosci. 24, 3703-3710.

Lin, D. Y., Zhang, S. Z., Block, E., and Katz, L. C. (2005). Encoding social signals in the mouse main olfactory bulb. Nature 434, 470-477. 
Lloyd-Thomas, A., and Keverne, E. B. (1982). Role of the brain and accessory olfactory system in the block to pregnancy in mice. Neuroscience 7, 907-913.

Lomas, D. E., and Keverne, E. B. (1982). Role of the vomeronasal organ and prolactin in the acceleration of puberty in female mice. J. Reprod. Fertil. 66, 101-107.

Luo, M., Fee, M. S., and Katz, L. C. (2003). Encoding pheromonal signals in the accessory olfactory bulb of behaving mice. Science 299, 1196-1201.

Ma, D., Allen, N. D., Van Bergen, Y. C., Jones, C. M., Baum, M. J., Keverne, E. B., and Brennan, P. A. (2002). Selective ablation of olfactory receptor neurons without functional impairment of vomeronasal receptor neurons in OMP-ntr transgenic mice. Eur. J. Neurosici. 16, 2317-2323.

Mackay-Sim, A., and Rose, J. D. (1986). Removal of the vomeronasal organ impairs lordosis in female hamsters: Effect is reversed by luteinising hormone-releasing hormone. Neuroendocrinology 42, 489-493.

Mandiyan, V. S., Coats, J. K., and Shah, N. M. (2005). Deficits in sexual and aggressive behaviors in Cnga2 mutant mice. Nat. Neurosci. 8, 1660-1662.

Martel, K. L., and Baum, M. J. (2007). Sexually dimorphic activation of the accessory, but not the main, olfactory bulb in mice by urinary volatiles. Eur. J. Neurosci. 26, 463-475.

Martel, K. L., Keller, M., Douhard, Q., Bakker, J., and Baum, M. J. (2007). Comparison of odor induced glomerular activation in the main olfactory bulb of aromatase knock-out and wild type female mice. Neurosci. Lett. 421, 101-105.

Martínez-García, F., Martínez-Ricós, J., Agustín-Pavón, C., Martínez-Hernández, J., Novejarque, A., and Lanuza, E. (2009). Refining the dual olfactory hypothesis: Pheromone reward and odour experience. Behav. Brain Res. 200, 277-286.

Martinez-Ricos, J., Agustin-Pavon, C., Lanuza, E., and Martinez-Garcia, F. (2008). Role of the vomeronasal system in intersexual attraction in female mice. Neuroscience 153, 383-395.

Meredith, M. (1986). Vomeronasal organ removal before sexual experience impairs male hamster mating behavior. Physiol. Behav. 36, 737-743.

Meredith, M. (1991). Sensory processing in the main and accessory olfactory systems: Comparisons and contrasts. J. Steroid Biochem. Mol. Biol. 39, 601-614.

Meredith, M. (1994). Chronic recording of vomeronasal pump activation in awake behaving hamsters. Physiol. Behav. 56, 345-354.

Meredith, M. (1998). Vomeronasal, olfactory, hormonal convergence in the brain. Cooperation or coincidence? Ann. NY Acad. Sci. 855, 349-361.

Meredith, M. (2001). Human vomeronasal organ function: a critical review of best and worst cases. Chem. Senses 26, 433-445.

Meredith, M., and Fewell, G. (2001). Vomeronasal organ: Electrical stimulation activates Fos in mating pathways and in GnRH neurons. Brain Res. 922, 87-94.

Meredith, M., and Howard, G. (1992). Intracerebroventricular LHRH relieves behavioral deficits due to vomeronasal organ removal. Brain Res. Bull. 29, 75-79.

Meredith, M., and O'Connell, R. J. (1979). Efferent control of stimulus access to the hamster vomeronasal organ. J. Physiol. 286, 301-316.

Munger, S. D., Leinders-Zufall, T., and Zufall, F. (2009). Subsystem organization of the mammalian sense of smell. Annu. Rev. Physiol. 71, 115-140.

Pankevich, D. E., Baum, M. J., and Cherry, J. A. (2004). Olfactory sex discrimination persists, whereas the preference for urinary odorants from estrous females disappears in male mice after vomeronasal organ removal. J. Neurosci. 24, 9451-9947.

Pankevich, D. E., Cherry, J. A., and Baum, M. J. (2006). Effect of vomeronasal organ removal from male mice on their preference for and neural Fos responses to female urinary odors. Behav. Neurosci. 120, 925-936. 
Pfeiffer, C. A., and Johnston, R. E. (1994). Hormonal and behavioral responses of male hamsters to females and female odors: Roles of olfaction, the vomeronasal system, and sexual experience. Physiol. Behav. 55, 129-138.

Pierman, S., Douhard, Q., Balthazart, J., Baum, M. J., and Bakker, J. (2006). Attraction thresholds and sex discrimination of urinary odorants in male and female aromatase knockout (ArKO) mice. Horm. Behav. 49, 96-104.

Powers, J. B., and Winans, S. S. (1975). Vomeronasal organ: Critical role in mediating sexual behavior of the male hamster. Science 187, 961-963.

Preti, G., Wysocki, C. J., Barnhart, K. T., Sondheimer, S. J., and Leyden, J. J. (2003). Male axillary extracts contain pheromones that affect pulsatile secretion of luteinizing hormone and mood in women recipients. Biol. Reprod. 68, 2107-2113.

Rajendren, G., Dudley, C. A., and Moss, R. L. (1990). Role of the vomeronasal organ in the male-induced enhancement of sexual receptivity in female rats. Neuroendocrinology 52, 368-372.

Romero, P. R., Beltramino, C. A., and Carrer, H. F. (1990). Participation of the olfactory system in the control of approach behavior of the female rat to the male. Physiol. Behav. 47, 685-690.

Savic, I., Hedén-Blomqvist, E., and Berglund, H. (2009). Pheromone signal transduction in humans: What can be learned from olfactory loss. Hum. Brain Mapp. 30, 3057-3065.

Scalia, F., and Winans, S. S. (1975). The differential projections of the olfactory bulb and accessory olfactory bulb in mammals. J. Comp. Neurol. 161, 31-55.

Shinohara, K., Morofushi, M., Funabashi, T., and Kimura, F. (2001). Axillary pheromones modulate pulsatile LH secretion in humans. NeuroReport 12, 893-895.

Spehr, M., Spehr, J., Ukhanov, K., Kelliher, K. R., Leinders-Zufall, T., and Zufall, F. (2006a). Parallel processing of social signals by the mammalian main and accessory olfactory systems. Cell. Mol. Life Sci. 63, 1476-1484.

Spehr, M., Kelliher, K. R., Li, X. H., Boehm, T., Leinders-Zufall, T., and Zufall, F. (2006b). Essential role of the main olfactory system in social recognition of major histocompatibility complex peptide ligands. J. Neurosci. 26, 1961-1970.

Stern, K., and McClintock, M. K. (1998). Regulation of ovulation by human pheromones. Nature 392, 177-179.

Stowers, L., Holy, T. E., Meister, M., Dulac, C., and Koentges, G. (2002). Loss of sex discrimination and male-male aggression in mice deficient for TRP2. Science 295, 1493-1500.

Thompson, M. L., and Edwards, D. A. (1972). Olfactory bulb ablation and hormonally induced mating in spayed female mice. Physiol. Behav. 8, 1141-1146.

Tirindelli, R., Dibattista, M., Pifferi, S., and Menini, A. (2009). From pheromones to behavior. Physiol. Rev. 89, 921-956.

Vandenbergh, J. G. (1969). Male odor accelerates female sexual maturation in mice. Endocrinology 84, 658-660.

Von Campenhausen, H., and Mori, K. (2000). Convergence of segregated pheromonal pathways from the accessory olfactory bulb to the cortex in the mouse. Eur. J. Neurosci. $12,33-46$.

Wesson, D. W., Keller, M., Douhard, Q., Baum, M. J., and Bakker, J. (2006). Enhanced urinary odor discrimination in female aromatase knockout (ArKO) mice. Horm. Behav. 49, 80-86.

Westberry, J., and Meredith, M. (2003a). The influence of chemosensory input and gonadotropin releasing hormone on mating behavior circuits in male hamsters. Brain Res. 974, $1-16$.

Westberry, J. M., and Meredith, M. (2003b). Pre-exposure to female chemosignals or intracerebral $\mathrm{GnRH}$ restores mating behavior in naive male hamsters with vomeronasal organ lesions. Chem. Senses 28, 191-196. 
Whitten, W. K. (1956). Modification of the oestrous cycle of the mouse by external stimuli associated with the male. J. Endocrinol. 13, 399-404.

Woodley, S. K., Cloe, A. L., Waters, P., and Baum, M. J. (2004). Effects of vomeronasal organ removal on olfactory sex discrimination and odor preferences of female ferrets. Chem. Senses 29, 659-669.

Wyatt, T. D. (2003). Pheromones and Animal Behaviour. Communication by Smell and Taste. Cambridge University Press, Cambridge, United-Kingdom.

Wysocki, C. J., Wellington, J. L., and Beauchamp, G. K. (1980). Access of urinary nonvolatiles to the mammalian vomeronasal organ. Science 207, 781-783.

Wysocki, C. J., and Preti, G. (2004). Facts, fallacies, fears, and frustrations with human pheromones. Anat. Rec. A Discov. Mol. Cell Evol. Biol. 281, 1201-1211.

Yoon, H., Enquist, L. W., and Dulac, C. (2005). Olfactory inputs to hypothalamic neurons controlling reproduction and fertility. Cell 123, 669-682. 